\title{
WEAR AND HARDNESS PROPERTIES OF CARBURIZED (AISI 1011) STEEL
}

\section{${ }^{*}$ Diyar A. Jabbar ${ }^{1}$}

\section{Zeyad D. Kadhim²}

Mohammed A. Abdulrazzaq ${ }^{3}$

1) Materials Engineering Department, Mustansiriyah University, Baghdad, Iraq

2) Assistant Prof. Dr., Materials Engineering Department, Mustansiriyah University, Baghdad, Iraq

3) Assistant Prof. Dr., Materials Engineering Department, Mustansiriyah University, Baghdad, Iraq

\begin{abstract}
In this research, the influence of carburizing process on low carbon steel AISI 1011 on the mechanical characteristics had been studied. It was found that hardness of this alloy increased for samples treated with carburizing procedure at $950^{\circ} \mathrm{C}$ for five hours it became $431.65 \mathrm{HV}$, while the hardness value of untreated specimens was $169.65 \mathrm{HV}$. Furthermore, surface roughness of metal increased for specimen treated with carburizing process, and it has become $1.98 \mu \mathrm{m}$. A pin on disk machine was employed for achieved the tests of wear under constant time $\mathbf{3 0}$ minutes for five different applied loads 10, 15, 20, 25 and $30 \mathrm{~N}$. The results illustrate there is an increment in wear rate with increasing the applied load. The maximum wear rate became $\left(6.2434 \times 10^{-8} \mathrm{gm} / \mathrm{cm}\right)$ at load $30 \mathrm{~N}$ for untreated specimens, while for carburized specimens the wear rate became $\left(4.7638 \times 10^{-8} \mathrm{gm} / \mathrm{cm}\right)$ at the same applied load. Also, it was observed that the wear resistance for carburized specimens higher than untreated samples.
\end{abstract}

Keywords: wear behavior; hardness; low carbon steel AISI (1011)

\section{Introduction}

Carbon steel is usually employed for many the industrial applications and manufacturing due to their easy fabrication and its cost is low [1]. When the carbon content is $<0.25$ in steel has been named as low carbon steel. In the case where the carbon content is high and lies in the range between $0.65 \%$ and $1.50 \%$, in such case, such steel is referred to as the high carbon steel, whereas the one that has the carbon content ranging from $0.25 \%$ to $0.65 \%$ has been referred to as the medium carbon steel [2]. The low carbon steel is known for its moderate strength and high ductility, it is utilized due to the fact that it has extensive fabrication characteristics for the structural purposes, in bridges, buildings, cars, and ships [3]. The carburization is a commonly utilized and important procedure for the surface hardening. The process involves the carbon addition to low carbon steel surface at a range of temperature which lies from $850^{\circ} \mathrm{C}$ to $950^{\circ} \mathrm{C}$ [4].Wear can be defined as one of the most destructive impacts which metal is exposed to. The metallic particles detachment and displacement from a metallic surface can be a result of contacting with (a) some other metal (metallic or adhesive wear), (b) a nonmetallic abrasive or a metallic (abrasion), or (c) moving gases or liquids (erosion). The 3 wear kinds can be sub-divided to wear under sliding friction or rolling friction and, additionally, based on whether the lubrication can be utilized or otherwise [5]. Though several investigations have demonstrated improved wear resistance of steel through surface treatment such as hardening or surface 
alloying [6]. Pandaa, R.R., et al, they studied wear and mechanical characteristics of the carburized mild steel. It was found that the mild steel carburized at a $950^{\circ} \mathrm{C}$ temperature gives the highest hardness, tensile strength and wear resistance values than that samples of mild steel which carburized at $850^{\circ} \mathrm{C}$ and $900^{\circ} \mathrm{C}$ [7]. Elzanaty, H., studied the impact of the carburization on the properties of the hardness and the wear of mild steel specimens. Remarked that metal and alloy characteristics may be altered through heating followed by the cooling under definite states, for making them appropriate for certain applications. Mild steel has been carburized at an $850^{\circ} \mathrm{C}$ to $950^{\circ} \mathrm{C}$ temperature range, where mild steel which has been carburized at a $950^{\circ} \mathrm{C}$ temperature is providing the optimal results for hardness and wear characteristics [8]. In the present work the effect of carburizing process on the mechanical properties of low carbon steel AISI 1011 have been investigated.

\section{Materials and method}

\subsection{Materials selection}

The material utilized in this research was low carbon steel AISI1011. This alloy's chemical analysis has been carried out by (the optical emission spectrometer of Thermo ARL3460) in Inspection and Engineering Rehabilitation (SIER) State Company in Baghdad. The outcomes, are correlated to American standard [9], are summarized in "Table 1". The chemical analysis was done at $\left(21^{\circ} \mathrm{C}\right)$ temperature and a $(44 \%)$ moisture rate.

\subsection{Surface treatment}

For stress relieve process, all specimens was carried out at temperature $\left(200^{\circ} \mathrm{C}\right)$ for $3 \mathrm{~h}$ with the use of the eclectic furnace [10].

\subsection{Samples preparation for carburizing process}

Samples were placed in a steel box which contains activated materials (80\% charcoal, $10 \% \mathrm{BaCO}_{3}, 9 \% \mathrm{CaCO}_{3}, 1 \% \mathrm{Na}_{2} \mathrm{CO}_{3}$ ) as shown in "fig. 1", that has been sealed by clay and placed afterwards in an electrical furnace in which it has been heated to $950^{\circ} \mathrm{C}$ and kept for 5 h., afterwards, it the samples have been quenched in the oil.

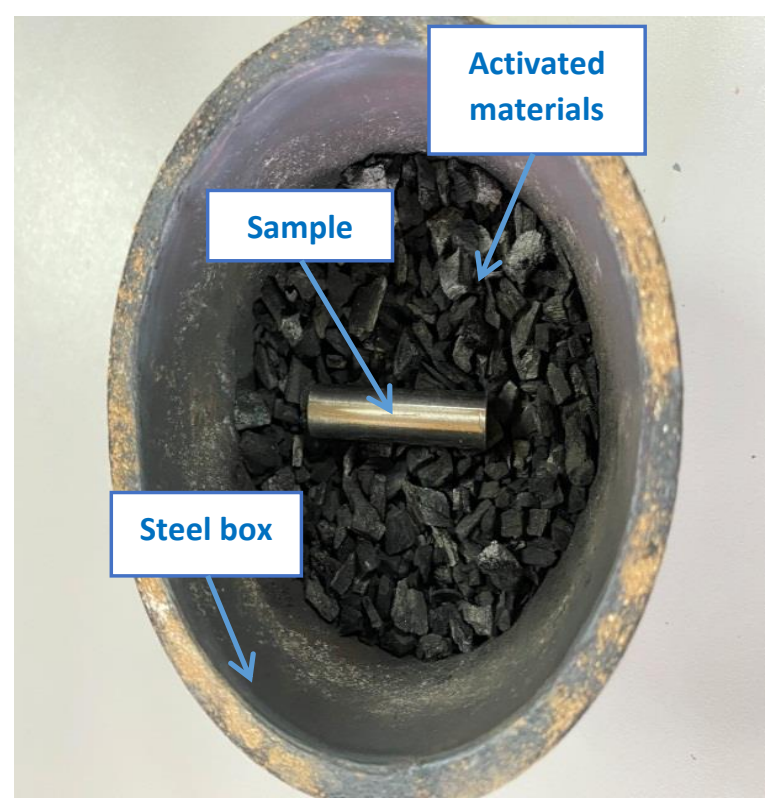

Figure 1. Carburizing box with wear specimen and carburizing components

\subsection{Examination the wear test}

A pin on disk machine as can be seen in "fig. 2" has been utilized for achieving wear tests in constant time (30 min) and a disk diameter equal to $18 \mathrm{~cm}$ with $(490 \mathrm{rpm})$ sliding velocity, at five different applied loads: 10, 15, 20, 25 and $30 \mathrm{~N}$. The samples have been weighted prior to and post each one of the tests with the use of sensitive balance, then the weight differences have been computed. The following equation has been utilized for the determination of the rates of the wear for every sample in $\mathrm{gm} / \mathrm{cm}[11]$. 
Wear rate $=\frac{\Delta W}{\pi D N t}$

$\Delta W=W_{1}-W_{2}$

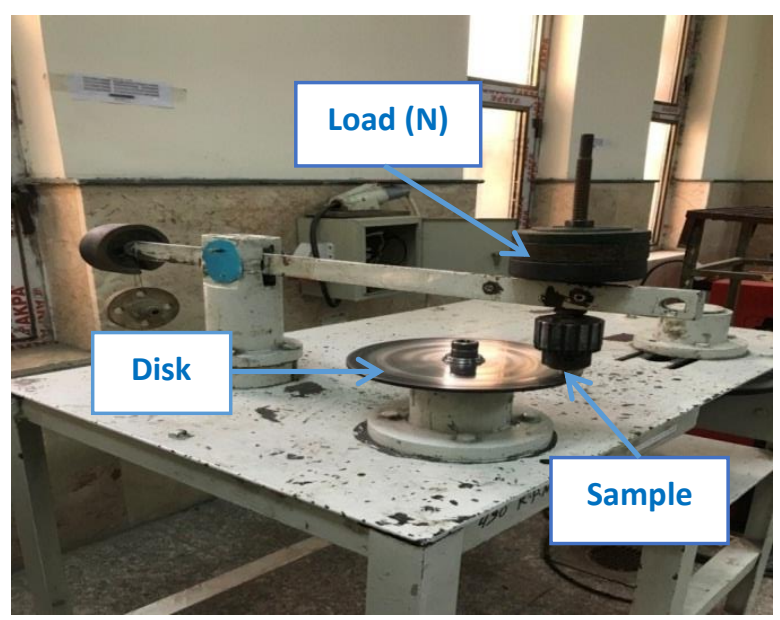

Figure 2. Wear test machine (pin-on-disk)

Table 1. Low carbon steel AISI 1011alloy chemical composition

\begin{tabular}{llllllllllll}
\hline Elements & $\begin{array}{l}\mathrm{C} \\
(\%)\end{array}$ & $\begin{array}{l}\mathrm{Si} \\
(\%)\end{array}$ & $\begin{array}{l}\mathrm{Mn} \\
(\%)\end{array}$ & $\begin{array}{l}\mathrm{P} \\
(\%)\end{array}$ & $\begin{array}{l}\mathrm{S} \\
(\%)\end{array}$ & $\begin{array}{l}\mathrm{Cr} \\
(\%)\end{array}$ & $\begin{array}{l}\mathrm{Mo} \\
(\%)\end{array}$ & $\begin{array}{l}\mathrm{Ni} \\
(\%)\end{array}$ & $\begin{array}{l}\mathrm{Al} \\
(\%)\end{array}$ & $\begin{array}{l}\mathrm{Cu} \\
(\%)\end{array}$ & $\begin{array}{l}\mathrm{Fe} \\
(\%)\end{array}$ \\
\hline Actual value & 0.0912 & 0.185 & 0.667 & 0.0233 & 0.0144 & 0.0652 & 0.0028 & 0.0338 & 0.0075 & 0.0457 & Bal. \\
Standard value & $\begin{array}{l}0.08- \\
0.13\end{array}$ & - & $0.6-0.9$ & $\begin{array}{l}0.04 \\
(\mathrm{Max})\end{array}$ & $\begin{array}{l}0.05 \\
(\mathrm{Max})\end{array}$ & - & - & - & - & - & - \\
\hline
\end{tabular}

\section{Results and Dis:}

\subsection{Microscopic examination test}

From "fig. 3", it may be observed that the low carbon steel AISI1011 micro-structure consists of light regions (ferrite) and dark regions (pearlite).

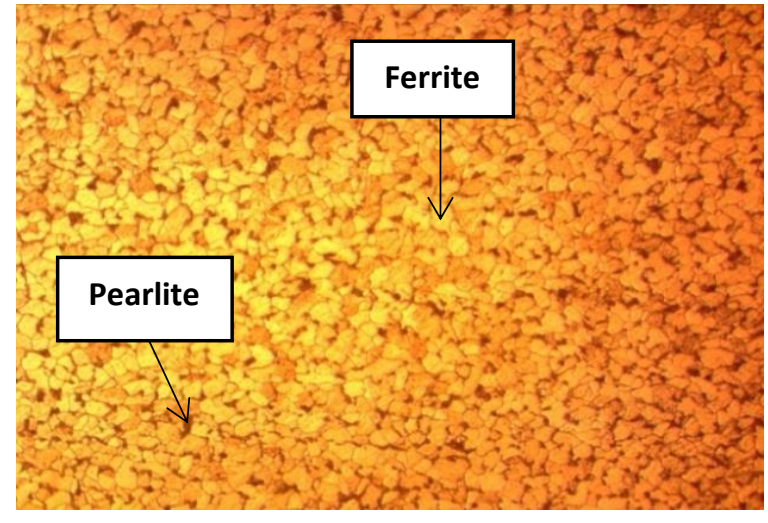

Figure 3. The micro-structure of the low carbon steel AISI1011 magnification (X 200) has shown 2 phases (which are the pearlite and the ferrite)

From "fig. 4" it can be seen the microstructure of the carburized steel, in carburizing process the harder the case or surface layer becomes, while the core of the steel remains tough and soft this is may be due to carbides exist in the edge of specimen, these carbides increases in the edge (near the surface) of specimen and decreases towards the center of specimen. Also as increasing carburization temperature leads to increases carbides formation.

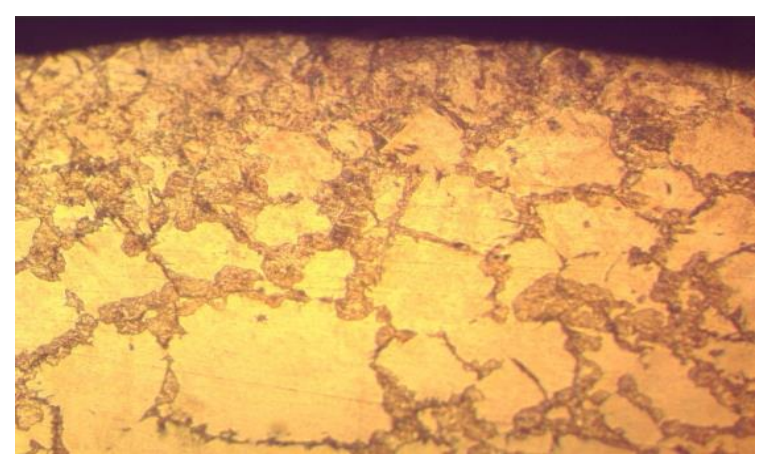

(A) 


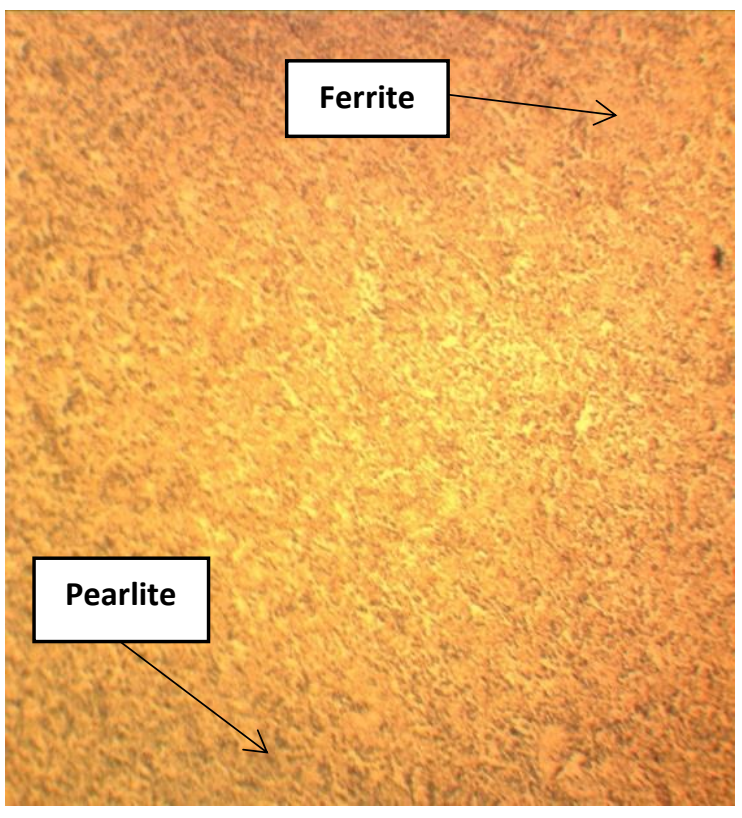

(B)

Figure 4. The micro-structure of the carburized low carbon steel AISI 1011, A: surface layer (ferrite and pearlite in some of the regions and of martensite in the other ones), B: core (pearlite and ferrite)

\subsection{XRD diffraction test}

The XRD test has been performed on tested samples for examining the phases existing in the material prior to and post the surface treatment.

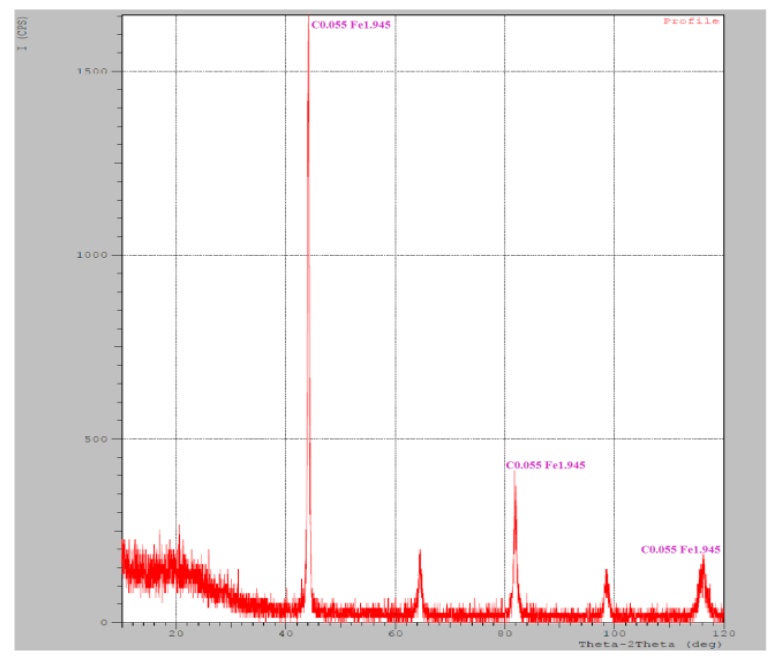

(A)

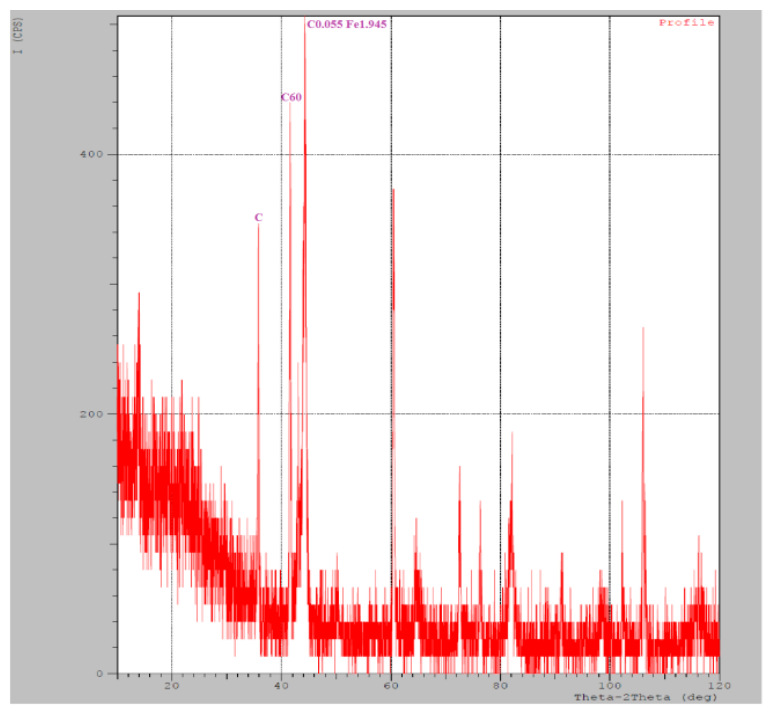

(B)

Figure 5. Pattern of XRD for (A) untreated AISI 1011steel; (B) carburized steel

\subsection{Microhardness results}

From "fig. 6", it can be seen the changement in hardness values. The hardness decreases towards the center of the sample this is due to carbon defusing from the surface to the center of specimen. The hardness for values was taken as a distance part $0.5 \mathrm{~mm}$ reaching to the core of the samples so numbers of hardness value become 8 . The hardness of low carbon steel increase with increase in the carburization temperature. 


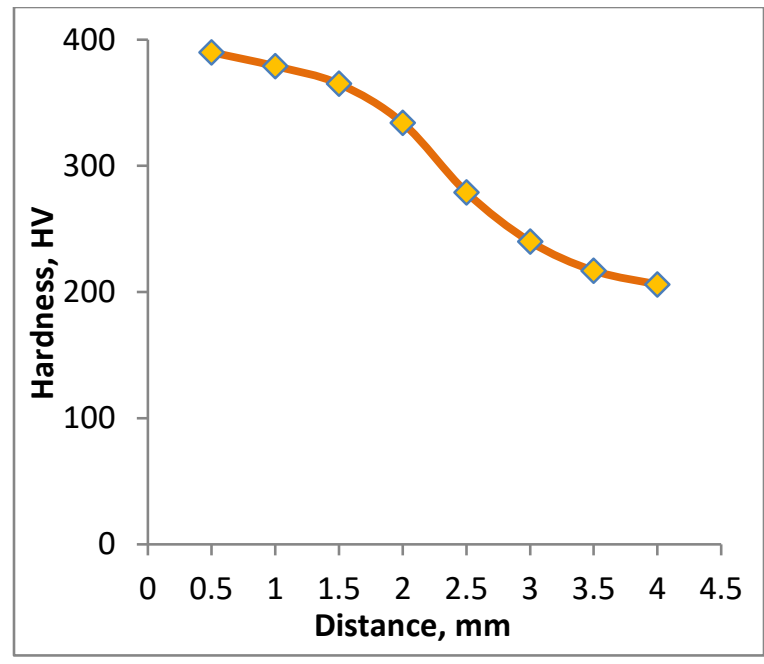

Figure 6. The relationship in between the hardness of the microscopic specimen carburized (5hours) and the distance from the specimen edge to the core.

\subsection{Surface roughness results}

The surface roughness for untreated specimens was $(0.92 \mu \mathrm{m})$, while surface roughness has increased for the samples which have been treated by the process of the carburization and became $(1.98 \mu \mathrm{m})$ at carburizing temperature $950^{\circ} \mathrm{C}$ and time of five hours. This is due to higher carburizing temperature leads to increase in the surface roughness of metal.

\subsection{Wear test}

From "fig. 7" and "fig. 8" it can be observed the rates of wear are load dependent and the results of wear tests indicate that the rates of wear are gradually increase at the applied load increases this is due to higher frictional heating at higher load increasing the temperature at the sliding surface, so the maximum wear rate became $6.2434 \times 10^{-8} \mathrm{gm} / \mathrm{cm}$ at load $30 \mathrm{~N}$ for untreated specimens, while for carburizing specimens the wear rate became $4.7638 \times 10^{-8}$ $\mathrm{gm} / \mathrm{cm}$ at the same applied load as shown in "Table 2" and "Table 3".

Table 2. Results of wear test for untreated low carbon steel AISI 1011

\begin{tabular}{cccc}
\hline $\begin{array}{c}\text { Applied } \\
\text { load (N) }\end{array}$ & $\begin{array}{c}\text { Time of } \\
\text { wear } \\
(\mathrm{min})\end{array}$ & $\begin{array}{c}\text { Difference in } \\
\text { weight }(\mathrm{gm})\end{array}$ & $\begin{array}{c}\text { Wear rate } \\
(\mathrm{gm} / \mathrm{cm})\end{array}$ \\
\hline 10 & 30 & 0.0197 & $2.3698 \times 10^{-8}$ \\
15 & 30 & 0.0266 & $3.1999 \times 10^{-8}$ \\
20 & 30 & 0.0325 & $3.9097 \times 10^{-8}$ \\
25 & 30 & 0.0421 & $5.0645 \times 10^{-8}$ \\
30 & 30 & 0.0519 & $6.2434 \times 10^{-8}$ \\
\hline
\end{tabular}

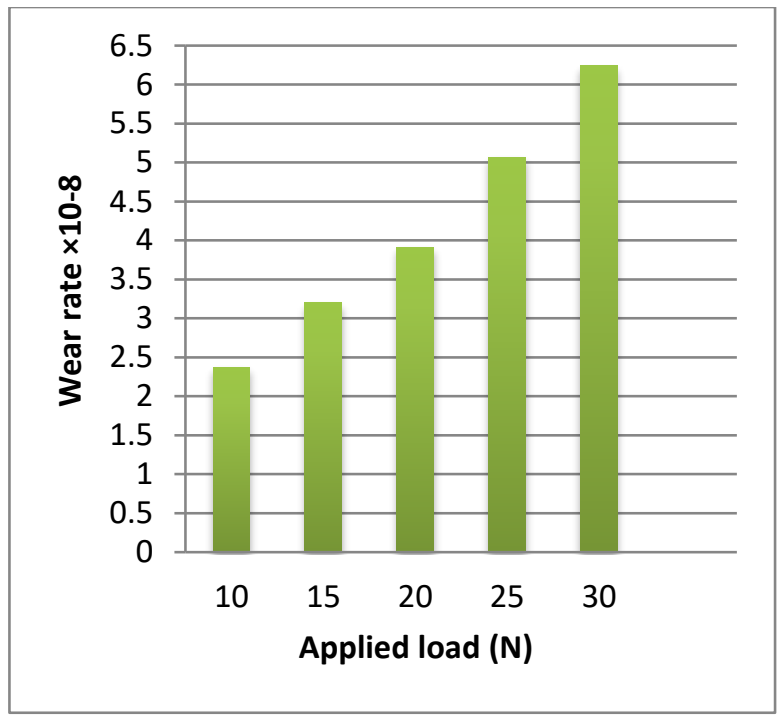

Figure 7. Wear rate with different applied loads for untreated specimens 
Table 3. Results of wear test for carburized low carbon steel AISI 1011

\begin{tabular}{cccc}
\hline $\begin{array}{c}\text { Applied } \\
\text { load (N) }\end{array}$ & $\begin{array}{c}\text { Time of } \\
\text { wear } \\
(\mathrm{min})\end{array}$ & $\begin{array}{c}\text { Difference in } \\
\text { weight }(\mathrm{gm})\end{array}$ & $\begin{array}{c}\text { Wear rate } \\
(\mathrm{gm} / \mathrm{cm})\end{array}$ \\
\hline 10 & 30 & 0.0156 & $1.8766 \times 10^{-8}$ \\
15 & 30 & 0.0194 & $2.3337 \times 10^{-8}$ \\
20 & 30 & 0.0263 & $3.1638 \times 10^{-8}$ \\
25 & 30 & 0.0318 & $3.8254 \times 10^{-8}$ \\
30 & 30 & 0.0396 & $4.7638 \times 10^{-8}$ \\
\hline
\end{tabular}

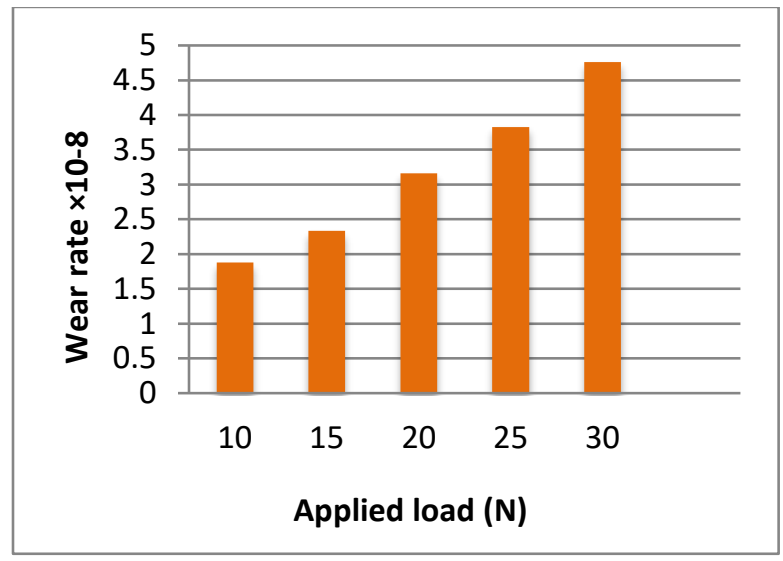

Figure 8. Wear rate with different applied loads for carburized specimens

From "fig. 9" it can be observed the wear rate decreases for the carburization specimens compared with untreated specimens this is due to increasing in the temperature of carburizing which leads to an increase in the spread of carbon atoms into the specimens, and this will lead to the formation of carbides that cause increase in metal hardness. The harder the metal, the better will be its wear resistance. In the carburizing process the wear resistance increase with increase in the carburization temperature. So the wear resistance for samples treated with carburizing method is higher than untreated specimens.

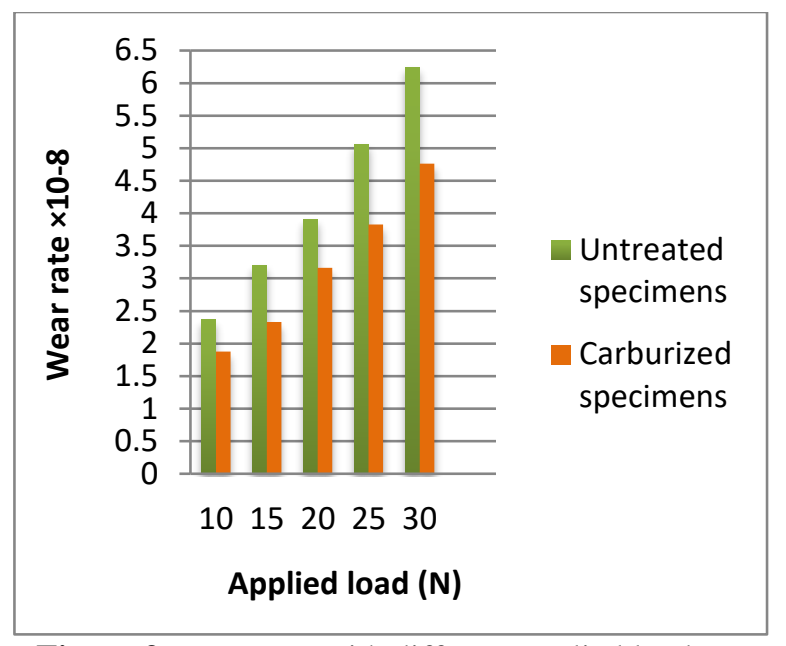

Figure 9. Wear rate with different applied loads for untreated and carburized specimens

\section{Conclusions}

1- Carburized specimens of low carbon steel (AISI1011) has wear resistance higher than untreated specimens for the same variables of wear test.

2- Carburizing process has shown increasing in metal hardness AISI 1011 steel, the maximum value of the hardness was $431.65 \mathrm{HV}$ at carburization temperature $950^{\circ} \mathrm{C}$ for five hours.

3 - There is an increment in the roughness of the surface for the samples which have been treated by carburization process, the metal surface roughness has been $1.98 \mu \mathrm{m}$.

\section{Acknowledgments}

The authors would like to thank the staff of Mustansiriyah

University (www.upomustansiriyah.edu.iq) Baghdad-Iraq, for their support in the present work.

\section{Conflict of interest}

The authors confirm that there is no conflict of interest. 


$\begin{array}{ll}\begin{array}{l}\text { Abbreviations } \\ \mathrm{W}_{1}\end{array} & \begin{array}{l}\text { the weight of the specimen } \\ \text { prior to the wear test }(\mathrm{gm})\end{array} \\ \mathrm{W}_{2} & \begin{array}{l}\text { the weight of the specimen } \\ \text { following the wear test }(\mathrm{gm})\end{array} \\ \mathrm{N} & \begin{array}{l}\text { the cycles number of the steel } \\ \text { disk }\end{array} \\ \mathrm{D} & \text { the used steel disk diameter } \\ \mathrm{t} & \begin{array}{l}\text { the sliding time } \\ \text { (min) }\end{array}\end{array}$

\section{References}

1. Tukur, S., et al. (2014). "Effect of tempering temperature on mechanical properties of medium carbon steel". International Journal of Engineering Trends and Technology, Vol. 9(15), No. 15, pp. 798-800.

2. Jaypuria, S. (2009). "Heat treatment of low carbon steel". NATIONAL INSTITUTE OF TECHNOLOGY, Department of Mechanical Engineering, Rourkela, india.

3. Abdulateef, M.M. (2015). "Enhancing the Fatigue Limit by Carbretion and Shot Peening For Low Carbon Steel (AISI 1010) ". M.Sc. Thesis, Department of Materials Engineering; Mustansiriya University, Iraq.

4. Totten, G.E., K. Funatani, and L. Xie. (2004). "Handbook of metallurgical process design". CRC press.

5. Daspattanayak, T. and K. Mohanty. (2013). "Effect of heat treatment on wear properties of plain carbon steel".

6. Gupta, V. and O. Pandey. (2000). "Wear characteristics of plain carbon steel". Indian
Journal of Engineering and Materials Sciences, Vol. 7, No 3, pp. 354-360.

7. Pandaa, R.R., et al. (2014). "Mechanical and wear properties of carburized low carbon steel samples". International Journal of Multidisciplinary and Current Research, Vol. 2, No. 9, pp. 109-112.

8. Elzanaty, H. (2014). "The effect of carburization on hardness and wear properties of the mild steel samples". International Journal of Innovation and Applied Studies, Vol. 6, No. 4, pp. 995-1001.

9. ASTM, A., Standard specification for steel, sheet and strip, hot-rolled, carbon, structural, high-strength low- alloy, high-strength lowalloy with improved formability, and ultrahigh strength. 2010.

10. Hasan, M.Q.S. (2018). "Effect of Roller Burnishing And Laser on Corrosion, Surface Roughness And Hardening of AISI 1017 Carbon Steel ". M.Sc. Thesis, Department of Materials Engineering; Mustansiriya University, Iraq.

11. Cardarelli, F. (2000). "Materials handbook". A Concise Desktop Reference, book, Springer, 2nd Edition, 1019-1034. 